\title{
Pain catastrophizing: rumination is a discriminating factor among individuals with different pain characteristic
}

Fernanda Salloume Sampaio BONAFÉ(a) Lucas Arrais CAMPOS(a) (if

João MARÔCO(b) (iD

Juliana Alvares Duarte Bonini CAMPOS(c) (ii)

(a) Universidade Estadual Paulista - Unesp, School of Dentistry, Araraquara, SP, Brazil.

(b) University Institute of Psychological, Social, and Life Sciences - ISPA, William James Center for Research, Lisbon, Portugal.

(c) Universidade Estadual Paulista - Unesp, School of of Pharmaceutical Sciences, Department of Food and Nutrition, Araraquara, SP, Brazil.

Declaration of Interests: The authors certify that they have no commercial or associative interest that represents a conflict of interest in connection with the manuscript.

Corresponding Author: Juliana Alvares Duarte Bonini Campos E-mail: juliana.campos@unesp.br

hitps://doi.org/10.1590/1807-3107bor-2019.vol33.0113

Submitted: February 22, 2019

Accepted for publication: August 23, 2019

Last revision: November 4, 2019
Abstract: The objective of this study was to compare the scores of the Helplessness, Magnification, Rumination, and Catastrophizing factors of the Pain Catastrophizing Scale (PCS) between samples with different pain characteristics. The psychometric properties of the PCS were evaluated in 1,151 Brazilian adults (78.9\% female; $38.6(\mathrm{SD}=10.8)$ years): 335 had no pain, 390 had been in pain for less than 3 months, 250 had been in recurring pain for more than 3 months, and 176 had been in continuous pain for more than 3 months. Confirmatory factor analysis (CFA) was conducted to verify the fit of the PCS models. Convergent validity and reliability were evaluated. Multi-group analysis was used to estimate the invariance of the factorial model. The global score for the PCS factors was obtained using the regression weight matrix for estimating factor scores from CFA. Analysis of variance was used to compare scores between samples. After excluding three items, the tri-factorial model showed adequate fit. The model parameters were invariant $\left(\Delta \chi_{(\lambda, i, \beta, R e s)}^{2} p \geq 0.05\right)$. Individuals experiencing pain showed higher scores for catastrophic thoughts. Individuals with pain for less than 3 months had the highest scores for Rumination $(p<0.001)$. The PCS showed valid, reliable, and invariant results for the sample of Brazilian adults in no pain or with different pain conditions. The PCS adequately discriminated individuals in pain from those without pain. Among those in pain, Rumination was the only discriminating factor.

Keywords: Catastrophization; Pain; Psychometrics.

\section{Introduction}

A catastrophic individual is someone who has excessive negative thoughts, which involves exaggerated threat values of pain, difficulty in distracting attention from the condition, or difficulty in dealing with the painful situation. ${ }^{1}$ This description was created based on the results of previous experimental and clinical studies ${ }^{2,3,4}$ that supported the creation of the Pain Catastrophizing Scale (PCS). ${ }^{5}$ This instrument is made up of 13 items, of which 3 are based on the distortion of reality and the tendency to exaggerate the threat value of pain, ${ }^{2} 5$ items are based on worry, fear or difficulty in decreasing the focus on and attention to pain ${ }^{4}$, and 5 items are from the Coping Strategies Questionnaire ${ }^{3}$ referring to inability to deal with pain. After the instrument was designed, exploratory research 
defined the best structural configuration for the PCS, ${ }^{5}$ resulting in a three-factor structure. This structure was tested and confirmed in different samples/ contexts such as university students, ${ }^{6,7,8}$ healthy individuals, ${ }^{9,10}$ and patients experiencing pain. . $^{810,11,12,13}$ However, there are some relative differences in item distribution between the instrument's three factors for different studies. ${ }^{711}$ The PCS can be used with a global score for Catastrophizing and/or its Magnification, Helplessness, and Rumination factors.

The catastrophizing global score, on the one hand, can facilitate analysis of the results and give a global view of individuals' catastrophizing thoughts. On the other hand, using the global score can result in the loss of theoretical or clinical information, which can restrict the identification of the most evident catastrophic factor of a specific condition, perhaps masking possible differences between individuals and making it more difficult to direct a clinical approach at a specific factor. This occurs because catastrophizing mechanisms are interpreted using theoretical resources that involve attention, appraisal process, and communal coping ${ }^{14,15}$ and these resources are closely related to the interpretation of the different factors in the PCS. For example, the Rumination factor is closely linked to the attention mechanism, which relates catastrophizing to the excessive attention toward an event. Thus, higher Rumination scores may lead to strategies aimed at reducing the attention and focus on the pain. The second mechanism suggests the catastrophizing of an event, with a primary appraisal (placing a value of threat and magnification of an event) that interacts with a secondary appraisal (inability to deal with the event). The primary appraisal is related to the Magnification and Rumination factors, while the secondary appraisal is related to the Helplessness factor. This theory is associated with the Beckian model of cognitive errors in which catastrophizing is compared with the dysfunctional thoughts of depressive individuals that exacerbate/ distort the threat value of stressors. In communal coping, catastrophizing is associated with a style of communicating ones afflictions with the aim of procuring closeness, support, or assistance from those around. Thus, the person magnifies, ruminates, and shows helplessness when facing a condition. ${ }^{14,15}$
Osman et al. ${ }^{7}$ attribute the increasing inclusion of catastrophizing in theoretical models researching pain to the development of the PCS. The literature ${ }^{15,16,17}$ indicates that catastrophizing plays an important role in studies on pain, contributing significantly to the perceived intensity of pain. ${ }^{17}$ However, for Sulivan et al. ${ }^{14}$ the relationship between catastrophizing and pain is based on a feedback process, in which catastrophizing thoughts influence the perception of pain just as pain may contribute to the occurrence of catastrophizing thoughts. This hypothesis was suggested as patients without pain show fewer catastrophizing thoughts than those in pain. ${ }^{10,14,18}$ However, few studies compared individuals with different clinical conditions, $8,19,20,21$ and only one study compared catastrophizing scores among samples of patients without pain, with acute pain, and with chronic pain. ${ }^{19}$ However, the authors ${ }^{19}$ considered the global score for catastrophizing, without analyzing its components.

Thus, this study aimed to compare the scores for Magnification, Rumination, Helplessness, and Catastrophizing of samples with different pain characteristics. The psychometric properties of the PCS for the sample were evaluated to verify the validity and reliability of the data.

\section{Methodology}

\section{Sample and study design}

This was a cross-sectional, observational study. Brazilian adults (aged $\geq 18$ years) seeking care in the Periodontics, Operative Dentistry, Emergency, Prosthodontics, Oral Medicine and Surgery Clinics at the School of Dentistry, Araraquara-UNESP in 2015 and 2016 who agreed to participate were included. Patients from the special needs clinic and those who did not respond to all of the items of the instrument were excluded.

The minimum sample size was estimated considering the proposal of Hair et al. ${ }^{22}$ who suggest 5 to 10 subjects per parameter of the model. As the factorial models to be tested for the PCS may have up to 29 parameters, the sample size was estimated to be from 145 to 290 subjects per group of pain level (4 levels), resulting in a minimum sample size from 
580 to 1,160 . Thus, 1,426 individuals were invited to participate, 1,214 agreed to participate (adherence rate $=85.1 \%$ ), and 1,151 responded to all items of the PCS $($ response rate $=94.8 \%$ ).

\section{Sample characterization}

The sample was characterized according to sex, age, marital status, and socio-economic level, which was estimated using the Brazilian Economic Classification Criterion. ${ }^{23}$

Participants were questioned about their pain following the International Association for the Study of Pain - IASP. ${ }^{24,25}$ They were first asked about the presence or absence of pain in the last 24 hours. Those not in pain in the previous 24 hours were included in the G0 group and responded how long ago their most recent experience of pain had been. Those with pain in the last 24 hours and pain onset within the last 3 months were included in group G1. People with pain onset more than 3 months before who reported crises/episodes of pain (recurring pain) were included in group G2, and who reported continuous pain were included in group G3. Participants also indicated the location of worst pain, classified as orofacial region (e.g. intraoral pain, headache, other sites on the face) or body.

\section{Pain catastrophizing scale (PCS)}

The PCS was developed in English by Sullivan et al. ${ }^{5}$ and includes three dimensions (Helplessness, Magnification and Rumination). It contains 13 items with a 5-point Likert-type scale ranging from "not at all" (0) to "all the time" (4). The reference period for responses is the individual's general experience of pain, with items preceded by the expression "When I am in pain..." (Table 1). Dr. Michael Sullivan provided two Portuguese versions of the instrument (for Portugal and Brazil).

\section{Face validation}

This study proposes a conciliated version based on the two existing Portuguese versions taking into account the orthographic treaty established between Portuguese-speaking countries in 2009. Divergences between versions were verified and discussed among the authors and finally one single version was established, presented in Table 1.

Table 1. Conciliated Portuguese version and the content validity ratio (CVR) for items of the Pain Catastrophizing Scale.

\begin{tabular}{|c|c|c|c|c|}
\hline \multirow{3}{*}{ Item } & \multicolumn{2}{|r|}{ Face validity } & \multicolumn{2}{|c|}{ Content validity } \\
\hline & Original version* Pain Catastrophizing Scale & Conciliated Portuguese version of Pain Catastrophizing Scale & \multirow{2}{*}{$\begin{array}{c}\text { Essential } \\
\left(n^{* *}\right)\end{array}$} & \multirow{2}{*}{ CVR } \\
\hline & When I'm in pain... & Quando estou com dor... & & \\
\hline 1 & I worry all the time about whether the pain will end. & Eu me preocupo o tempo inteiro se a dor irá terminar. & 8 & 1.00 \\
\hline 2 & I feel I can't go on. & Eu sinto que não consigo continuar. & 8 & 1.00 \\
\hline 3 & $\begin{array}{l}\text { It's terrible and I think it's never going to get } \\
\text { any better. }\end{array}$ & É terrível e penso que nunca vai melhorar. & 8 & 1.00 \\
\hline 4 & It's awful and I feel that it overwhelms me. & É horrível e sinto que é demais pra mim. & 6 & $0.50^{* * *}$ \\
\hline 5 & I feel I can't stand it anymore. & Eu sinto que não consigo aguentar mais. & 8 & 1.00 \\
\hline 6 & I become afraid that the pain will get worse. & Eu fico com medo que a dor se torne ainda pior. & 8 & 1.00 \\
\hline 7 & I keep thinking of other painful events. & Eu fico pensando sobre outras situações de dor. & 7 & 0.75 \\
\hline 8 & I anxiously want the pain to go away. & Eu quero ansiosamente que a dor desapareça. & 8 & 1.00 \\
\hline 9 & I can't seem to keep it out of my mind. & Eu não consigo deixar de pensar nisso. & 7 & 0.75 \\
\hline 10 & I keep thinking about how much it hurts. & Eu fico pensando no quanto dói. & 7 & 0.75 \\
\hline 11 & $\begin{array}{c}\text { I keep thinking about how badly I want the pain } \\
\text { to stop. }\end{array}$ & Eu fico pensando no quanto eu quero que a dor pare. & 7 & 0.75 \\
\hline 12 & $\begin{array}{c}\text { There's nothing I can do to reduce the intensity } \\
\text { of the pain. }\end{array}$ & $\begin{array}{l}\text { Não há nada que eu possa fazer para reduzir a intensidade } \\
\text { da dor. }\end{array}$ & 8 & 1.00 \\
\hline 13 & I wonder whether something serious may happen. & Eu penso que algo grave poderia acontecer. & 8 & 1.00 \\
\hline
\end{tabular}

"Sullivan et al. '; " number of experts who judged the item to be essential; ${ }^{* * *}$ below the recommended value $\left(\mathrm{CVR}_{8 ; 0.05}=0.693\right)$. 
The conciliated version of the PCS was tested in a pilot study. Twenty-five adult patients ( $81 \%$ female) with a mean age of $45.73(\mathrm{SD}=10.41)$ seeking care at the School of Dentistry, Araraquara (FOAR-Unesp), Brazil, participated in this stage. The PCS was completed during a face-to-face interview and the time needed to complete the form was recorded. Individuals were questioned about the difficulty of understanding terms/words in each item to compute the incomprehension index (II).

The mean time for PCS completion was 3.05 $(\mathrm{SD}=1.30)$ minutes. All items were understood without difficulty by the participants (II $=0 \%$ ).

\section{Content validity}

The content validity of the conciliated version was evaluated by 8 experts and the content validity ratio (CVR) was calculated based on the experts' responses to the essentiality of each item ("essential", "useful but not essential", and "not necessary"). ${ }^{26}$ The experts involved in the study work with pain and use psychometric instruments on a daily basis. Decisions were made using the proposal by Wilson et al. ${ }^{27}$ considering a level of significance of $5 \%\left(\mathrm{CVR}_{8 ; 0.05}=0.693\right)$.

\section{Procedures and ethical aspects}

The data were collected by an individual face-toface interview in the waiting rooms of the institution clinics before the scheduled appointment. Participation was voluntary and participants signed an informed consent form. This study was approved by the Ethics Committee on Human Research of the institution.

\section{Evaluation of psychometric properties}

The psychometric properties of the PCS were analyzed using the following theoretical models:

$\mathrm{M}_{1}$ : Tri-factorial Model proposed by Sullivan et al. ${ }^{5}$ : 13 items distributed into three factors: "Helplessness" (items 1, 2, 3, 4, 5, 12), "Magnification" (items 6, 7, 13), and "Rumination" (items 8, 9, 10, 11).

$\mathrm{M}_{2}$ : Tri-factorial Model proposed by Osman et al.7: 13 items distributed into three factors: "Helplessness" (items 1, 2, 3, 4, 12), "Magnification" (items 6, 7, 13) and "Rumination" (items 5, 8, 9, 10, 11).
$\mathrm{M}_{3}$ : Tri-factorial Model proposed by Meyer, et al..11: 13 items distributed into three factors: "Magnification" (items 1, 2, 3, 4, 5), "Magnification" (items 6, 7, 13), and "Rumination" (items 8, 9, 10, 11, 12).

To improve the quality of the data modification indices, the models were refined and labelled with the letter " $R$ " ( $M_{1} R, M_{2} R$, and $\left.M_{3} R\right)$. To improve the refined model, the second order hierarchical factor described

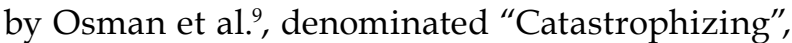
was proposed. This model was identified with the letters "HM".

The psychometric sensitivity of the PCS items was evaluated, with absolute values of kurtosis $(\mathrm{Ku})<7$ and skewness $(\mathrm{Sk})<3$ deemed adequate. ${ }^{28,29}$ Validity and factorial, convergent and discriminant validity were verified to evaluate the construct.

Factorial validity was evaluated using confirmatory factor analysis (CFA) with the maximum likelihood method of estimation. The indices for evaluating the quality of fit used were the chi-square per degree of freedom ratio $\left(\chi^{2} / \mathrm{df}\right)$, comparative fit index (CFI), goodness of fit index (GFI), and root mean square error of approximation (RMSEA). ${ }^{28,29}$ The values deemed to indicate adequate fit of the model to the data were $\chi^{2} / \mathrm{df} \leq 2.00$, CFI and GFI $\geq 0.90$, and RMSEA $<0.10 .28,29$ Items with factorial weights $(\lambda)<0.50$ were removed. Correlations between item errors were included when indicated by the Modification Indices, computed based on Lagrange Multipliers $(\mathrm{LM}>11, \mathrm{p}<0.001){ }^{28}$

Indices based on Information Theory, Akaike Information Criterion (AIC), Browne-Cudeck Criterion (BCC), and Bayes Information Criterion (BIC) were used and the lowest values indicated the most parsimonious factorial model. ${ }^{28}$

Convergent and discriminant validity were based on the proposal by Fornell and Larcker. ${ }^{30}$ Convergent validity was deemed adequate when the Average Variance Extracted $(\mathrm{AVE}) \geq 0.50 .^{22,28}$ Discriminant validity was deemed adequate when $A V E_{(i)}$ and $A V E_{(\mathrm{j})} \geq r_{(\mathrm{ij})}^{2}\left(r_{(\mathrm{ij})}^{2}\right.$ : square of the correlation between factors $_{\mathrm{i}}$ and $\left.\mathrm{j}_{\mathrm{j}}\right)^{30}$

The reliability of the data was verified. Values for standardized Cronbach's alpha (a) and Composite Reliability $(\mathrm{CR}) \geq 0.70$ indicated adequate internal consistency. ${ }^{22,28}$ 
After fitting the second order hierarchical model (HM) for the total sample, the invariance of the model parameters in independent samples was conducted. For this, the sample was randomly subdivided into two equal parts ("Test Sample" and "Validation Sample"). The parameters analyzed were: factorial weights $(\lambda)$, intercepts (i), structural weights $(\beta)$, and residues' variance/covariance (Res). Multigroup analysis was conducted with the chi-square test $\left(\Delta \chi^{2}\right)$. Parameters were deemed invariant when $\mathrm{p}_{\Delta x^{2}} \geq 0.05$. Weak invariance was considered when there was only invariance of the factorial weights $(\lambda)$ between the models of the independent samples. Scalar invariance was obtained when the factorial weights $(\lambda)$, intercepts (i), and structural weights $(\beta)$ were invariant. Strict invariance was considered when factorial weights $(\lambda)$, intercepts (i), structural weights $(\beta)$, and residues' variance/covariance (Res) were invariant and strong invariance when at least scalar invariance was verified. ${ }^{28}$

\section{Comparison of global weighted scores}

The global scores for the Magnification, Rumination, Helplessness and Catastrophizing factors were evaluated for the four samples with different pain characteristics (G0, G1, G2, and G3). The global score of these factors was calculated using the matrix of weights $(\mathrm{W})$ obtained in the confirmatory factorial analysis ${ }^{28}$, which attributes a weight to each item in the instrument. The weights were adjusted to maintain the value of the global score of the factors compatible with the minimum-maximum value of the scale response options (from 0 to 4 ). To compute the global scores of the factors, the value of the individual's response given to each item should be multiplied by the weight of that item and, finally, all these values should be summed.

Analysis of variance (ANOVA-Welch) was used to compare the global scores between samples once the heteroscedasticity of the data had been determined (Levene's test ( $p$ 0.001). Multiple comparisons were made using the Games-Howell post-hoc test. The level of significance was $5 \%$.

IBM SPSS Statistics (v.22, SPSS An IBM Company, Chicago, USA) and AMOS 22.0 (SPSS An IBM Company, Chicago, USA) were used for data analyses.

\section{Results}

The conciliated Portuguese version of the PCS and the results of the content validity ratio are shown in Table 1. Only item 4 was not considered essential by the experts. However, this is the preliminary stage and decisions made regarding the items should be accompanied by the results of confirmatory factor analysis.

The characteristics of the sample studied are shown in Table 2. In all groups the majority of participants were female, married or in a common law relationship and from a C socio-economic level. As for the pain characteristics, the individuals reported not being in pain at the time of the interview, and most recent experience of pain was $47.46(\mathrm{SD}=113.34)$ days before.

Descriptive statistics of participants' responses are shown in Table 3. All items on the PCS showed adequate psychometric sensitivity in all groups $(\mathrm{Ku}<7$ and $\mathrm{Sk}<3)$, with no indication of a severe violation of normality.

Validity and reliability results of the PCS model are shown in Table 4.

Upon analyzing models M1, M2 and M3, the modification indices indicated saturation of items 1 and 12 in more than one factor ( $\mathrm{LM}=57.694-74.597)$ and suggested correlations between the error of item 8 and the errors of items 1, 6, 7, 10, 11, and 13 $(\mathrm{LM}=12.215-100.492)$. Thus, it was decided to refine the models by excluding items 1,8 , and 12 . In order to fit $M_{2}\left(M_{2} R\right)$, it was also necessary to exclude item 5 , as it was saturated in two factors (Rumination and Helplessness) (LM = 303.348-360.879).

The Helplessness, Magnification, and Rumination factors showed adequate convergent validity and reliability. Discriminant validity between the Helplessness and Rumination factors was only adequate after refining the models $\left(M_{1} R, M_{2} R\right.$, and $\left.M_{3} R\right)$.

The refined $\mathrm{M} 1$ and $\mathrm{M} 3$ models $\left(\mathrm{M}_{1} \mathrm{R}\right.$ and $\left.\mathrm{M}_{3} \mathrm{R}\right)$ had the same structure and $M_{2} R$ had fewer items. Thus, to construct the second order hierarchical model (HM), it was decided to use the one that best preserved the original proposal $\left(M_{1} R / M_{3} R\right)$.

The hierarchical model $(\mathrm{HM})$ showed adequate fit to the sample $\left(X^{2} / \mathrm{df}=6.001 ; \mathrm{CFI}=0.982 ; \mathrm{GFI}=0.967\right.$; RMSEA $=0.066)$ and its factorial structure is shown in Figure. 
- Pain catastrophizing: rumination is a discriminating factor among individuals with different pain characteristic

Table 2. Characteristics of participants according to group (n).

\begin{tabular}{|c|c|c|c|c|c|}
\hline \multirow{2}{*}{ Characteristic } & \multicolumn{5}{|c|}{ Sample* } \\
\hline & Go & G1 & G2 & G3 & Total \\
\hline $\mathrm{N}$ & 335 & 390 & 250 & 176 & 1,151 \\
\hline \multicolumn{6}{|l|}{ Age } \\
\hline mean years & 38.09 & 36.68 & 38.12 & 44.65 & 38.62 \\
\hline standard-deviation & 10.70 & 9.94 & 11.05 & 10.22 & 10.77 \\
\hline \multicolumn{6}{|l|}{ Sex } \\
\hline Male & 84 & 106 & 32 & 21 & 243 \\
\hline Female & 251 & 284 & 218 & 155 & 908 \\
\hline \multicolumn{6}{|l|}{ Marital status } \\
\hline Single & 102 & 144 & 62 & 29 & 337 \\
\hline Married/Common law relationship & 194 & 203 & 157 & 111 & 665 \\
\hline Widowed & 10 & 8 & 9 & 7 & 34 \\
\hline Divorced & 29 & 35 & 22 & 29 & 115 \\
\hline \multicolumn{6}{|l|}{ Socio-economic level** } \\
\hline$A / B$ & 142 & 133 & 92 & 55 & 422 \\
\hline C & 173 & 219 & 128 & 106 & 626 \\
\hline $\mathrm{D} / \mathrm{E}$ & 20 & 38 & 30 & 15 & 103 \\
\hline \multicolumn{6}{|l|}{ Location of pain } \\
\hline Orofacial & 173 & 323 & 120 & 35 & 651 \\
\hline Body & 162 & 67 & 130 & 141 & 500 \\
\hline
\end{tabular}

*Groups: $\mathrm{G0}=$ no pain; $\mathrm{G} 1$ = pain $<3$ months; $\mathrm{G} 2$ = recurrent pain $\geq 3$ months; $\mathrm{G} 3$ = continuous pain $\geq 3$ months. "A/B: R\$12,870.00 or US\$3,984.52; C: R\$2,165.00 or US\$670.28; D/E: R\$768.00 or US\$237.77 - Exchange rate of 1 Brazilian real was 3.23 US dollars provided by the Brazilian Central Bank on September 23, 2016.

Table 3. Descriptive statistics (mean and standard deviation/kurtosis/skewness) of participants' responses to the items on the Pain Catastrophizing Scale according to groups.

\begin{tabular}{|c|c|c|c|c|c|}
\hline \multirow{3}{*}{ Item } & \multicolumn{5}{|c|}{ Sample* } \\
\hline & \multicolumn{5}{|c|}{ Mean (Standard Deviation)/Kurtosis/Skewness } \\
\hline & G0 & G1 & G2 & G3 & Total \\
\hline 1 & $1.62(1.40) /-1.07 / 0.55$ & $2.48(1.42) /-1.50 /-0.28$ & $2.00(1.44) /-1.46 / 0.14$ & $1.93(1.54) /-1.56 / 0.16$ & $2.04(1.48) /-1.52 / 0.11$ \\
\hline 2 & $0.76(1.08) / 1.94 / 1.62$ & $1.37(1.42) /-0.88 / 0.74$ & $1.16(1.34) /-0.27 / 1.01$ & $1.25(1.43) /-0.65 / 0.90$ & $1.13(1.34) /-0.21 / 1.04$ \\
\hline 3 & $0.67(1.09) / 3.00 / 1.92$ & $1.45(1.54) /-1.16 / 0.65$ & $1.27(1.38) /-0.58 / 0.87$ & $1.35(1.49) /-0.93 / 0.77$ & $1.17(1.41) /-0.43 / 1.00$ \\
\hline 4 & $0.63(1.06) / 2.87 / 1.91$ & $1.45(1.51) /-1.16 / 0.62$ & $1.21(1.40) /-0.52 / 0.93$ & $1.44(1.47) /-1.08 / 0.66$ & $1.15(1.40) /-0.48 / 0.98$ \\
\hline 5 & $0.66(1.07) / 3.00 / 1.92$ & $1.35(1.45) /-0.87 / 0.77$ & $1.16(1.35) /-0.34 / 1.00$ & $1.20(1.38) /-0.47 / 0.95$ & $1.09(1.35) /-0.12 / 1.11$ \\
\hline 6 & $1.08(1.11) / 0.89 / 1.24$ & $1.95(1.44) /-1.44 / 0.25$ & $1.64(1.39) /-1.01 / 0.58$ & $1.60(1.40) /-1.08 / 0.57$ & $1.58(1.38) /-0.96 / 0.63$ \\
\hline 7 & $0.55(0.93) / 4.20 / 2.09$ & $0.98(1.31) / 0.11 / 1.20$ & $1.00(1.28) / 0.15 / 1.17$ & $0.99(1.32) / 0.34 / 1.27$ & $0.86(1.22) / 0.86 / 1.42$ \\
\hline 8 & $1.80(1.38) /-1.23 / 0.41$ & $2.59(1.39) /-1.46 /-0.37$ & $2.34(1.42) /-1.57 /-0.09$ & $2.36(1.47) /-1.52 /-0.23$ & $2.27(1.44) /-1.55 /-0.06$ \\
\hline 9 & $0.97(1.32) / 0.14 / 1.22$ & $1.81(1.60) /-1.57 / 0.24$ & $1.43(1.52) /-1.08 / 0.67$ & $1.48(1.59) /-1.25 / 0.63$ & $1.43(1.54) /-1.16 / 0.64$ \\
\hline 10 & $1.06(1.24) / 0.31 / 1.16$ & $1.97(1.54) /-1.56 / 0.11$ & $1.62(1.50) /-1.29 / 0.45$ & $1.56(1.53) /-1.28 / 0.54$ & $1.57(1.49) /-1.22 / 0.53$ \\
\hline 11 & $1.63(1.37) /-1.05 / 0.54$ & $2.52(1.47) /-1.46 /-0.35$ & $2.12(1.51) /-1.57 / 0.02$ & $2.19(1.51) /-1.59 /-0.08$ & $2.12(1.49) /-1.55 / 0.03$ \\
\hline 12 & $0.77(1.10) / 1.99 / 1.64$ & $1.31(1.42) /-0.79 / 0.81$ & $1.12(1.37) /-0.31 / 1.03$ & $1.14(1.39) /-0.38 / 1.01$ & $1.08(1.34) /-0.12 / 1.10$ \\
\hline 13 & $0.96(1.18) / 0.92 / 1.33$ & $1.43(1.52) /-1.18 / 0.62$ & $1.38(1.48) /-1.01 / 0.71$ & $1.40(1.50) /-1.07 / 0.69$ & $1.28(1.43) /-0.74 / 0.84$ \\
\hline
\end{tabular}


Table 4. Confirmatory factorial analysis (CFA), average variance extracted (AVE), and reliability (CR, $\alpha$ ) of the Pain Catastrophizing Scale (PCS) fit for the sample.

\begin{tabular}{|c|c|c|c|c|c|c|c|c|c|c|c|c|}
\hline \multirow{2}{*}{ Model* } & \multicolumn{10}{|c|}{ CFA** $^{* *}$} & \multirow{2}{*}{$C R$} & \multirow{2}{*}{$\alpha$} \\
\hline & $\lambda$ & $\chi^{2} / d f$ & $\mathrm{CFI}$ & GFI & RMSEA & $\mathrm{AIC}$ & $\mathrm{BIC}$ & $\mathrm{BCC}$ & $r$ & AVE & & \\
\hline \multicolumn{13}{|l|}{ PCS } \\
\hline$M_{1}$ & $0.59-0.91$ & 10.843 & 0.947 & 0.912 & 0.093 & 730.287 & 876.690 & 731.002 & $0.83-0.92$ & $0.56-0.72$ & $0.79-0.91$ & $0.79-0.91$ \\
\hline$M_{1} R$ & $0.66-0.92$ & 6.001 & 0.982 & 0.967 & 0.066 & 238.025 & 354.138 & 238.469 & $0.80-0.90$ & $0.56-0.76$ & $0.79-0.92$ & $0.79-0.92$ \\
\hline$M_{2}$ & $0.61-0.89$ & 19.753 & 0.899 & 0.848 & 0.128 & 1.282 .689 & 1.429 .093 & 1.283 .404 & $0.89-0.93$ & $0.56-0.67$ & $0.79-0.91$ & $0.79-0.91$ \\
\hline$M_{2} R$ & $0.65-0.92$ & 5.350 & 0.986 & 0.976 & 0.062 & 170.397 & 276.413 & 170.765 & $0.81-0.90$ & $0.56-0.76$ & $0.79-0.91$ & $0.79-0.90$ \\
\hline$M_{3}$ & $0.58-0.92$ & 10.894 & 0.947 & 0.913 & 0.093 & 733.440 & 879.843 & 734.155 & $0.83-0.91$ & $0.56-0.66$ & $0.79-0.91$ & $0.79-0.90$ \\
\hline$M_{3} R$ & $0.66-0.92$ & 6.001 & 0.982 & 0.967 & 0.066 & 238.025 & 354.138 & 238.469 & $0.80-0.90$ & $0.56-0.76$ & $0.79-0.92$ & $0.79-0.92$ \\
\hline
\end{tabular}

${ }^{*} M_{1}$ : Tri-factorial Model by Sullivan et al. ${ }^{5} ; M_{1} R: M_{1}$ Refined; $M_{2}$ : Tri-factorial Model by Osman et al. ${ }^{7} ; M_{2} R: M_{2}$ Refined; $M_{3}$ : Tri-factorial Model by Meyer et al. ${ }^{11} ; M_{3} R: M_{3}$ Refined; " $\lambda$ : Factor loading, $\chi^{2} / d f$ : ratio between chi-square and degrees of freedom, CFI: comparative fit index, GFI: goodness of fit index, RMSEA: root mean square error of approximation, AIC: Akaike Information Criterion, BCC: Browne-Cudeck Criterion (BCC), BIC: Bayes Information Criterion, r: correlation between two factors, CR: Composite Reliability, $\alpha$ : standardized Cronbach's alpha.

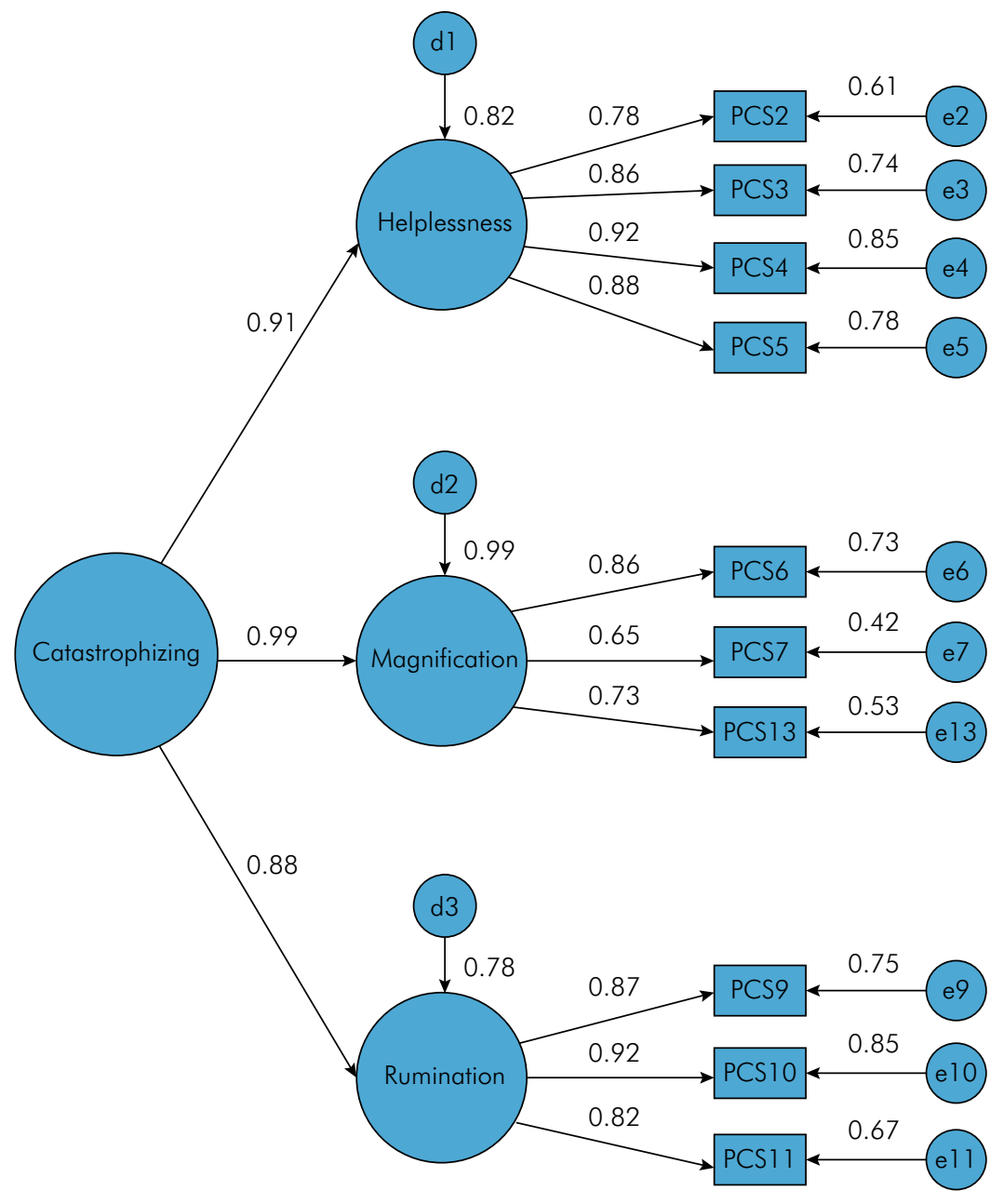

Figure. Second order hierarchical model (HM) of the Pain Catastrophizing Scale applied to the total sample. 
- Pain catastrophizing: rumination is a discriminating factor among individuals with different pain characteristic

Table 5. Weights (W) obtained from the regression matrix attributed to items on the Pain Catastrophizing Scale (PCS) to compute the global score of the "Helplessness", "Magnification", "Rumination", and "Catastrophizing" factors.

\begin{tabular}{|c|c|c|c|c|c|c|c|c|c|c|}
\hline \multirow{2}{*}{ Factor } & \multicolumn{10}{|c|}{ W } \\
\hline & $1+2$ & $1+3$ & It4 & $1+5$ & $1+6$ & It7 & $1+9$ & $1+10$ & $1+11$ & $1+13$ \\
\hline Helplessness & 0.11 & 0.17 & 0.32 & 0.22 & 0.07 & 0.02 & 0.02 & 0.03 & 0.01 & 0.03 \\
\hline Magnification & 0.04 & 0.06 & 0.12 & 0.08 & 0.26 & 0.11 & 0.06 & 0.11 & 0.04 & 0.12 \\
\hline Rumination & 0.01 & 0.02 & 0.04 & 0.02 & 0.07 & 0.03 & 0.22 & 0.40 & 0.16 & 0.03 \\
\hline Catastrophizing & 0.04 & 0.07 & 0.12 & 0.09 & 0.24 & 0.09 & 0.07 & 0.12 & 0.05 & 0.11 \\
\hline
\end{tabular}

Table 6. Comparison of the mean \pm standard-deviation of the scores for the Helplessness, Magnification, Rumination, and Catastrophizing factors of the Pain Catastrophizing Scale between the groups with differing pain characteristics.

\begin{tabular}{lcccc}
\hline \multirow{2}{*}{ Sample* } & \multicolumn{4}{c}{ Mean \pm standard-deviation } \\
\cline { 2 - 5 } & Helplessness & Magnification & Rumination & Catastrophizing \\
\hline G0 & $0.73 \pm 0.93^{\mathrm{a}}$ & $0.89 \pm 0.88^{\mathrm{a}}$ & $1.08 \pm 1.05^{\mathrm{a}}$ & $0.90 \pm 0.89^{\mathrm{a}}$ \\
G1 & $1.48 \pm 1.29^{\mathrm{b}}$ & $1.63 \pm 1.20^{\mathrm{b}}$ & $1.92 \pm 1.34^{\mathrm{b}}$ & $1.65 \pm 1.20^{\mathrm{b}}$ \\
G2 & $1.26 \pm 1.22^{\mathrm{b}}$ & $1.41 \pm 1.18^{\mathrm{b}}$ & $1.59 \pm 1.32^{\mathrm{c}}$ & $1.42 \pm 1.19^{\mathrm{b}}$ \\
G3 & $1.36 \pm 1.26^{\mathrm{b}}$ & $1.44 \pm 1.18^{\mathrm{b}}$ & $1.60 \pm 1.30^{\mathrm{c}}$ & $1.45 \pm 1.18^{\mathrm{b}}$ \\
Total & $1.19 \pm 1.21$ & $1.34 \pm 1.15$ & $1.56 \pm 1.29$ & $1.35 \pm 1.15$ \\
ANOVA-Welch & 32.981 & 34.419 & 31.654 & 34.723 \\
p-value & $<0.001$ & $<0.001$ & $<0.001$ & $<0.001$ \\
\hline
\end{tabular}

*Groups: $G 0$ = no pain; $G 1$ = pain $<3$ months; $G 2$ = recurrent pain $\geq 3$ months; $G 3$ = continuous pain $\geq 3$ months ${ }^{a, b}$ different letters indicate statistical difference. Games-Howell post-hoc test, $\alpha=5 \%$.

The second order HM showed strong invariance in independent samples $\left(\Delta x^{2} \lambda(7)=5.252(p=0.629)\right.$; $\Delta \chi^{2} \mathrm{i}(10)=8.158(\mathrm{p}=0.613) ; \Delta \chi^{2} \beta(3)=4.287(\mathrm{p}=0.232)$; $\left.\Delta \chi^{2} \operatorname{Res}(10)=14.183(\mathrm{p}=0.165)\right)$. The fit of this model (HM) was also adequate for each sample with differing pain characteristics $\left(\mathrm{G} 0: \mathrm{x}^{2} / \mathrm{df}=3.715 ; \mathrm{CFI}\right.$ $=0.962 ; \mathrm{GFI}=0.934 ; \mathrm{RMSEA}=0.090 ; \mathrm{G} 1: \mathrm{X}^{2} / \mathrm{df}=2.183$; $\mathrm{CFI}=0.987 ; \mathrm{GFI}=0.966 ; \mathrm{RMSEA}=0.055 ; \mathrm{G} 2: \mathrm{x}^{2} / \mathrm{df}=3.152$; $\mathrm{CFI}=0.970 ; \mathrm{GFI}=0.925 ; \mathrm{RMSEA}=0.093 ; \mathrm{G} 3: \mathrm{x}^{2} / \mathrm{df}=1.895$; $\mathrm{CFI}=0.978 ; \mathrm{GFI}=0.934 ; \mathrm{RMSEA}=0.072$ ).

The weights attributed to each item of the PCS used for computing the global score of the "Helplessness", "Magnification", "Rumination" and "Catastrophizing" factors are shown in Table 5.

Table 6 shows comparisons of the mean PCS global scores among groups. Higher scores for Catastrophizing, Helplessness, Magnification and Rumination were associated to the presence of pain. Only the Rumination factor significantly discriminated individuals in pain for less than 3 months (G1) from those who in pain for more than 3 months (G2 and
G3), with a higher score for those with pain onset within the last 3 months (G1).

\section{Discussion}

This study presented evidence of the validity, reliability, and invariance of the PCS in groups without pain or with different pain characteristics. Moreover, a new proposal for computing the global score based on weighted items and the comparison of scores for the Rumination, Magnification and Helplessness factors between groups is provided.

Confirmatory factor analysis indicated that the theory of defining catastrophizing based on the Rumination, Magnification, and Helplessness factors by Sullivan et al. ${ }^{5}$ is viable for people without pain or with different pain characteristics. However, the best fit to the model occurred after excluding 3 items (1, 8 and 12). Studies ${ }^{7,11,13}$ had reported that some items of the PCS were saturated in more than one factor or in different factors to the original 
proposal; in other words, some items share different theories, justifying their exclusion. As for item 12, it was originally developed with another 4 items following the theoretical reasoning of Spanos. ${ }^{4}$ However, after exploratory factor analysis, ${ }^{5}$ item 12 was allocated to the Helplessness factor (related to inability to deal with pain) while the other components were allocated to the Rumination factor (related to worry, fear, and tendency to increase the focus and attention on pain). Meyer et al., ${ }^{11}$ in turn, proposed allocating item 12 in the Rumination factor. This lack of consensus may suggest difficulty in interpreting the content of the item, indicating the need for its theoretical re-evaluation. Items 1 and 8 also appear to be in need of re-evaluation of their theoretical contribution to their respective factors (Rumination and Helplessness). Shen et al. ${ }^{13}$ had already pointed out in a study with a Brazilian sample that item 8 did not adequately saturate in the Rumination factor. Certain studies ${ }^{6,12,13}$ had shown that item 1 contributed the least to the operationalization of the Helplessness factor (lowest factorial weight). Upon analyzing the theoretical content of this item, it also seemed to reflect concepts attributed to the Rumination factor as it deals with "worry all the time about whether the pain will end". Another piece of evidence on the need for theoretical clarification for these three items was that, after their exclusion, the two factors involved (Rumination and Helplessness) began to show adequate discriminant validity.

Thus, after excluding these items the refined tri-factorial model $\left(\mathrm{M}_{1} \mathrm{R} / \mathrm{M}_{2} \mathrm{R}\right)$ showed adequate fit for the sample (Table 4), as well as the second order hierarchical model (HM) (Figure). These models were invariant in the independent samples, indicating the adequate external validity of the results. ${ }^{28}$ Given the possibility of using the first or second order model, this must be a strategic choice. Working with Catastrophizing as a single measure may yield results easier to be interpreted and more objective for screening the degree of catastrophizing thoughts in a specific sample. On the other hand, synthesizing those catastrophizing thoughts in one single variable might be insufficient for detecting specific factors (rumination, helplessness, and magnification) involved in the process and providing directed and more effective interventions. Sulivan ${ }^{15}$ highlights the need for research on all factors of catastrophizing thoughts, as well as on clarifying the target for treating and handling the patient in pain.

The results of this study are in line with studies that suggest that pain influences catastrophizing thoughts: ${ }^{14,19}$ in groups with pain (G1, G2, and G3), the scores for catastrophizing, helplessness, magnification, and rumination were all higher than in G0 (no pain). These results also indicate the adequate discriminant criterion validity of $\mathrm{PCS},{ }^{28}$ as a statistically significant difference was found among samples with different conditions. It is accepted that, in the face of a painful event there is i) greater demand for care/worry; ii) a greater perception of pain as threatening, and iii) greater inability to deal with pain compared with individuals who are not in pain.

Of the individuals who reported pain within the previous 24 hours, the scores for Rumination were significantly higher among those who reported onset of pain within the last 3 months (G1). This finding might be supported by the attention mechanism theory, ${ }^{14,31}$ which suggests that catastrophizing thoughts are related to directing greater attention towards pain. This attention mechanism can be seen as a defense mechanism, ${ }^{31,32}$ an attempt to signal that something is not well, especially when dealing with a recent event (pain for less than 3 months). We should bear in mind that this theory relates attention with Rumination scores. Sullivan ${ }^{15}$ also suggests that although catastrophizing appears to be a maladaptive process, in these situations, catastrophizing the painful condition may have certain benefits such as greater mobilization of those around us and of health care agents in resolving the problem. It has been suggested that care for these individuals should therefore be directed at reducing the focus and attention on pain and should begin by revealing their clinical situation, clarifying the causes, signs, symptoms, and evolution of the disease. This strategy may, consequently, contribute to reducing the threat value of pain and provide appropriate conditions for the individual to develop his or hers own abilities to deal with it. Thus, the identification of rumination may be a clinically relevant strategy to establish a therapeutic approach involving not only the direct intervention for pain 
but also the minimization of the rumination process. This strategy may make treatment more resolvable. As shown in this study, the dentist is able to identify this condition, however, it will often be necessary to elaborate a multiprofessional treatment to manage it, including experts from Psychology who can certainly contribute to the formulation of an integral protocol to approach pain.

The Magnification, Helplessness, and Catastrophizing (global) factors were not capable of discriminating individuals who reported onset of pain more than 3 months before (G2 and G3) from those with onset within less than 3 months (G1). This is worrying as it is expected that living with a painful condition, i.e. those who reported having been in pain for a longer time (G2 and G3), especially those in continuous pain, would evaluate pain as less threatening and would be more skillful at dealing with it. This was not found, indicating the need to include intervention strategies for these patients, aiming to decrease the threat value of pain and improving coping abilities. Sullivan ${ }^{15}$ reports that cases of chronic illness/pain should be considered maladaptive situations and suggests that interventions concerning interpersonal aspects may be more important than using techniques directed specifically at the symptoms of the disease. We should also consider that, as mentioned above, the relationship between catastrophizing and pain is a feedback process ${ }^{14}$ and thus interventions towards modulating catastrophizing thoughts could be important in controlling pain and lessening suffering. ${ }^{33}$

In this study, it was proposed that scores for Rumination, Magnification, Helplessness, and Catastrophizing should be calculated based on the matrix of weights obtained in the confirmatory factorial analysis. The objective of this proposal was to obtain a more accurate measurement, i.e., with less error. The authors who proposed the PCS 5 recommend calculating scores based on summing the responses. ${ }^{1}$ The first criticism of summing concerns the impossibility of working with the scale when items are excluded ${ }^{28}$ Based on the confirmatory factorial analysis, certain items were excluded from the model to obtain valid and reliable results for the sample, and thus the originally proposed maximum score with 13 items (52) cannot be used in an instrument with 10 items (maximum score of 40). In addition, the variables studied are latent, i.e., they are not measured directly and, consequently, should be operationalized through manifest variables (items). However, validation studies indicate that the manifestation of the latent variable is not always the same in all items..$^{28}$ Therefore, when summing scores or even when using the simple arithmetic mean to compute the global score, the items are deemed to manifest the latent variable in the same way, which is unrealistic. For this reason, this study proposed a method that provides a contributing weight for each item of the factor to be estimated, taking into account its peculiarities and the error inherent in the measure for the sample studied. We therefore consider this strategy to be more adequate for achieving more accurate measurement. ${ }^{28,34}$

This way of computing the global score may appear difficult in clinical practice. However, by having the weights values of each item and using digital interfaces, these data can easily be used as a "mask". For example, through the development of a cell phone application that would automatically generate a score for catastrophizing, rumination, helplessness, and magnification by inserting a person's responses. We also suggest that further studies be conducted to verify the contribution of pain and/or its specific characteristics to catastrophizing thoughts.

One limitation of the study is that the causal relationship between catastrophizing thoughts and pain could not be established due to the study design (cross-sectional). However, cross-sectional studies are the most commonly used in preliminary research such as validation studies and enable hypotheses to be generated based on the relationships found between variables. Another limitation of validation studies is that the results are valid and reliable for samples with similar characteristics to the sample used for validation. For samples that are different or in other contexts, the psychometric properties need to be re-evaluated and new weight estimates should be obtained. Also, the large gender imbalance of the sample was a limitation. However, this was a characteristic of the population attending the institution where the data collection was performed. 


\section{Conclusion}

After excluding three items, the PCS showed valid, invariant, and reliable results for a sample of Brazilian adults in no pain or with different pain conditions. The PCS adequately discriminated individuals with and without pain. Among those in pain, Rumination was the only discriminating factor.

\section{References}

1. Sullivan MJ. PCS: The pain catastrophizing scale: user manual. 2009.

2. Chaves JF, Brown JM. Spontaneous cognitive strategies for the control of clinical pain and stress. J Behav Med. 1987 Jun;10(3):263-76. https://doi.org/10.1007/BF00846540

3. Rosenstiel AK, Keefe FJ. The use of coping strategies in chronic low back pain patients: relationship to patient characteristics and current adjustment. Pain. 1983 Sep;17(1):33-44. https://doi.org/10.1016/0304-3959(83)90125-2

4. Spanos NP, Radtke-Bodorik HL, Ferguson JD, Jones B. The effects of hypnotic susceptibility, suggestions for analgesia, and the utilization of cognitive strategies on the reduction of pain. J Abnorm Psychol. 1979 Jun;88(3):282-92. https://doi.org/10.1037/0021-843X.88.3.282

5. Sullivan MJ, Bishop SR, Pivik J. The Pain Catastrophizing Scale: development and validation. Psychol Assess. 1995 Dec;7(4):524-32. https://doi.org/10.1037/1040-3590.7.4.524

6. D'Eon JL, Harris CA, Ellis JA. Testing factorial validity and gender invariance of the pain catastrophizing scale. J Behav Med. 2004 Aug;27(4):361-72. https://doi.org/10.1023/B:JOBM.0000042410.34535.64

7. Osman A, Barrios FX, Kopper BA, Hauptmann W, Jones J, O’Neill E. Factor structure, reliability, and validity of the Pain Catastrophizing Scale. J Behav Med. 1997 Dec;20(6):589-605. https://doi.org/10.1023/A:1025570508954

8. Van Damme S, Crombez G, Bijttebier P, Goubert L, Van Houdenhove B. A confirmatory factor analysis of the Pain Catastrophizing Scale: invariant factor structure across clinical and non-clinical populations. Pain. 2002 Apr;96(3):319-24. https://doi.org/10.1016/S0304-3959(01)00463-8

9. Osman A, Barrios FX, Gutierrez PM, Kopper BA, Merrifield T, Grittmann L. The Pain Catastrophizing Scale: further psychometric evaluation with adult samples. J Behav Med. 2000 Aug;23(4):351-65. https://doi.org/10.1023/A:1005548801037

10. Pallegama RW, Ariyawardana A, Ranasinghe AW, Sitheeque M, Glaros AG, Dissanayake WP, et al. The Sinhala version of the pain catastrophizing scale: validation and establishment of the factor structure in pain patients and healthy adults. Pain Med. 2014 Oct;15(10):1734-42. https://doi.org/10.1111/pme.12529

11. Meyer K, Sprott H, Mannion AF. Cross-cultural adaptation, reliability, and validity of the German version of the Pain Catastrophizing Scale. J Psychosom Res. 2008 May;64(5):469-78. https://doi.org/10.1016/i.jpsychores.2007.12.004

12. $X_{\cup} X$, Wei $X$, Wang F, Liu J, Chen $H$, Xiong $Y$, et al. Validation of a Simplified Chinese version of the pain catastrophizing scale and an exploration of the factors predicting catastrophizing in pain clinic patients. Pain Physician. 2015 Nov; 18(6):E1059-72.

13. Sehn F, Chachamovich E, Vidor LP, Dall-Agnol L, Souza IC, Torres IL, et al. Cross-cultural adaptation and validation of the Brazilian Portuguese version of the pain catastrophizing scale. Pain Med. 2012 Nov;13(11):1425-35. https://doi.org/10.1111/j.1526-4637.2012.01492.x

14. Sullivan MJ, Thorn B, Haythornthwaite JA, Keefe F, Martin M, Bradley LA, et al. Theoretical perspectives on the relation between catastrophizing and pain. Clin J Pain. 2001 Mar;17(1):52-64. https://doi.org/10.1097/00002508-200103000-00008

15. Sullivan MJ. The communal coping model of pain catastrophising: clinical and research implications. Can Psychol. 2012;53(1):32-41. https://doi.org/10.1037/a0026726

16. Goubert L, Crombez G, Van Damme S. The role of neuroticism, pain catastrophizing and pain-related fear in vigilance to pain: a structural equations approach. Pain. 2004 Feb;107(3):234-41. https://doi.org/10.1016/i.pain.2003.11.005

17. Kjøgx H, Kasch H, Zachariae R, Svensson P, Jensen TS, Vase L. Experimental manipulations of pain catastrophizing influence pain levels in patients with chronic pain and healthy volunteers. Pain. 2016 Jun;157(6):1287-96. https://doi.org/10.1097/i.pain.0000000000000519

18. Quartana PJ, Buenaver LF, Edwards RR, Klick B, Haythornthwaite JA, Smith MT. Pain catastrophizing and salivary cortisol responses to laboratory pain testing in temporomandibular disorder and healthy participants. J Pain. 2010 Feb;11(2):186-94. https://doi.org/10.1016/i.jpain.2009.07.008

19. Hübscher M, Moloney N, Rebbeck T, Traeger A, Refshauge KM. Contributions of mood, pain catastrophizing, and cold hyperalgesia in acute and chronic low back pain: a comparison with pain-free controls. Clin J Pain. 2014 Oct;30(10):886-93. https://doi.org/10.1097/AJP.0000000000000045 
- Pain catastrophizing: rumination is a discriminating factor among individuals with different pain characteristic

20. Campbell CM, Kronfli T, Buenaver LF, Smith MT, Berna C, Haythornthwaite JA et al. Situational versus dispositional measurement of catastrophizing: associations with pain responses in multiple samples. J Pain. 2010 May;1 1(5):443-453.e2. https://doi.org/10.1016/i.jpain.2009.08.009

21. Kremer R, Granot M, Yarnitsky D, Crispel Y, Fadel S, Best LA, et al. The role of pain catastrophizing in the prediction of acute and chronic postoperative pain. Open Pain J. 2013;6(1):176-82. https://doi.org/10.2174/1876386301306010176

22. Hair JF, Black WC, Babin B, Anderson RE, Tatham RL. Multivariate data analysis. 6th ed. City: Prentice Hall; 2005.

23. Associação Brasileira de Empresas de Pesquisa - ABEP. Critério de Classificação Econômica Brasil; 2015. São Paulo: Associação Brasileira de Empresas de Pesquisa; 2015.

24. Pain terms: a list with definitions and notes on usage. Pain. 1979 Jun;6(3):249-52.

25. International Association for the Study of Pain - IASP. Classification of chronic pain: description of chronic pain syndromes and definitions of pain terms. Seattle: IASP Press; 1994.

26. Lawshe CH. Quantitative Approach to Content Validity. Pers Psychol. 1975 28(4):563-575. https://doi.org/10.1111/j.1744-6570.1975.tb01393.x

27. Wilson FR, Pan W, Schumsky DA. Recalculation of the Critical Values for Lawshe's Content Validity Ratio. Meas Eval Couns Dev. 2012 Jul;45(3):197-210. https://doi.org/10.1177/0748175612440286

28. Maroco J. Análise de equações estruturais: fundamentos teóricos, software \& aplicações. Pero Pinheiro: ReportNumber; 2014.

29. Kline RB. Principles and practice of structural equation modeling. New York: Guilford; 1998.

30. Fornell C, Larcker DF. Evaluating Structural Equation Models with Unobservable Variables and Measurement Error. J Mark Res. 1981;18(1):39-50. https://doi.org/10.1177/002224378101800104

31. Eccleston C, Crombez G. Pain demands attention: a cognitive-affective model of the interruptive function of pain. Psychol Bull. 1999 May; 125(3):356-66. https://doi.org/10.1037/0033-2909.125.3.356

32. Linton SJ, Shaw WS. Impact of psychological factors in the experience of pain. Phys Ther. 2011 May;91(5):700-11. https://doi.org/10.2522/pti.20100330

33. Wood BM, Nicholas MK, Blyth F, Asghari A, Gibson S. Catastrophizing mediates the relationship between pain intensity and depressed mood in older adults with persistent pain. J Pain. 2013 Feb;14(2):149-57. https://doi.org/10.1016/i.jpain.2012.10.011

34. Anastasi A. Psychological testing. 6th ed. New York: Macmillan; 1988. 